Supporting Information

\title{
Measuring Equilibrium Binding at Quantum Dot Surfaces using Cyclic Voltammetry
}

Danielle A. Henckel, Michael J. Enright, Noushyar Panahpour Eslami, Daniel M. Kroupa, Daniel R. Gamelin, Brandi M. Cossairt*

\section{Table of contents}

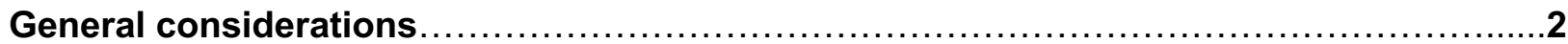

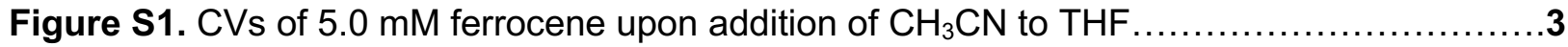

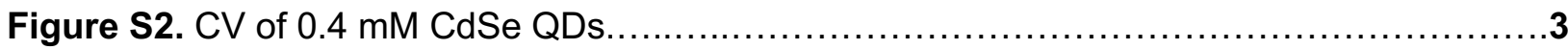

Figure S3. $\mathrm{i}_{\mathrm{pa}}(\mu \mathrm{A})$ versus ratio of CdSe QD $(3.0 \mathrm{~nm})$ binding sites / Fc-hexSH ratio .................4

Figure S4. CVs of $1.1 \mathrm{mM} \mathrm{Fc-hexSH}$ with increasing amounts of $0.1 \mathrm{~mL}$ CdSe QD $(2.6 \mathrm{~nm})$

solution aliquots

Figure S5. Experimental and simulated CVs of $1.3 \mathrm{mM} \mathrm{Fc-hexSH}$ with increasing amounts of CdSe QDs (3.0 nm, low concentration regime)

Figure S6. CVs of $1.3 \mathrm{mM}$ Fc-hexSH with increasing amounts of CdSe QDs (3.0 nm, high concentration regime)

Figure S7. Simulations using different magnitudes of $\mathrm{K}_{\mathrm{eq}}$ for $\mathrm{Fc}$-hexSH with $17.0 \mu \mathrm{M}$ of $2.6 \mathrm{~nm}$ CdSe QDs

Figure S8. CVs of $0.4 \mathrm{mM} \mathrm{FcCOOH}$ with increasing amounts of CdSe QDs $(2.6 \mathrm{~nm}) \ldots \ldots \ldots \ldots$

Figure S9. CV of $0.6 \mathrm{mM} \mathrm{FcCOOH}$ with increasing amounts of CdSe QDs (3.0 nm) $\ldots \ldots \ldots \ldots .7$

Figure S10. UV-vis of $2.6 \mathrm{~nm}$ and $3.0 \mathrm{~nm}$ CdSe QDs used in this study $\ldots \ldots \ldots \ldots \ldots \ldots \ldots \ldots . \ldots \ldots$

Figure S11. Peak current $\left(i_{p}\right)$ versus square root of scan rate $\left((\mathrm{V} / \mathrm{s})^{1 / 2}\right)$ of $\mathrm{Fc}$-hexSH to determine diffusion coefficient.

Figure S12. Peak current $\left(\mathrm{i}_{\mathrm{p}}\right)$ versus square root of scan rate $\left((\mathrm{V} / \mathrm{s})^{1 / 2}\right)$ of $\mathrm{FcCOOH}$ to determine diffusion coefficient 8

Table S1. Fitting parameters for electrochemical simulations $\ldots \ldots \ldots \ldots \ldots \ldots \ldots \ldots \ldots \ldots \ldots \ldots . .9$

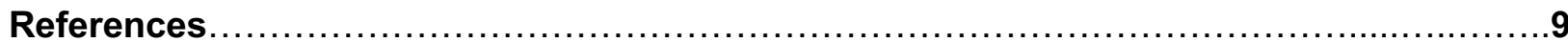




\section{General considerations}

All electrochemical experiments were performed in a $\mathrm{N}_{2}$ filled glove box. The electrolyte $\left[{ }^{\mathrm{n}} \mathrm{Bu}_{4} \mathrm{~N}\right]\left[\mathrm{PF}_{6}\right]$ used in cyclic voltammetry experiments was recrystallized two times in EtOH and dried overnight under vacuum at $100^{\circ} \mathrm{C}$. Ferrocene carboxylic acid $(\mathrm{FcCOOH})$ was recrystallized in $\mathrm{CH}_{3} \mathrm{CN}$ and toluene. Ferrocene was recrystallized once in pentane. Amino ferrocene $\left.(\mathrm{FcNH})_{2}\right)$ ferrocene hexane thiol ( $\mathrm{Fc}$-hexSH), and ferrocene bromide $(\mathrm{FcBr})$ were obtained from Sigma Aldrich and used as received. Glassy carbon working electrodes ( $\mathrm{CH}$ Instruments and BASi), platinum auxiliary electrode (BASi) and a $\mathrm{Ag}$ wire pseudo reference electrode in a Vycor-fritted compartment (BASi) filled with $0.15 \mathrm{M}$ [ $\left.{ }^{n} \mathrm{Bu}_{4} \mathrm{~N}\right]\left[\mathrm{PF}_{6}\right]$ in $\mathrm{CH}_{3} \mathrm{CN}$ were used. Glassy carbon electrodes with a diameter of $3.0 \mathrm{~mm}$ were polished using $0.05,0.3$ and 1.0 micron polishing powder ( $\mathrm{CH}$ Instruments) followed by 5 min sonication cycles in deionized water. All experiments were referenced to an internal ferrocene standard added after the experiment. Ultra-high purity acetonitrile used in cyclic voltammetry (Burdick and Johnson) was dried over alumina overnight, subjected to 3 freeze pump thaw cycles, brought in the glove box, filtered, and stored over $3 \AA$ molecular sieves. Tetrahydrofuran was purified on a solvent system and stored over $3 \AA$ molecular sieves. No resistance compensation was made in the electrochemical experiments.

CdSe nanocrystals were synthesized according to a previously reported procedure. ${ }^{1,2}$ Cadmium oxide (CdO, 99.9\%) and selenium (Se, 100 mesh, 99.999\%), were obtained from Sigma Aldrich and used as received. Oleic acid (OA, 90\%) and 1-octadecene (1-ODE, 90\%) were obtained from Sigma Aldrich and used after purification by distillation. In a $50-\mathrm{mL}$, 3-neck flask, $300 \mathrm{mg} \mathrm{CdO}, 2 \mathrm{~mL} \mathrm{OA}$, and $20 \mathrm{~mL}$ 1-ODE degassed under vacuum while stirring for 10 min. Nitrogen was introduced and the mixture was heated to $250^{\circ} \mathrm{C}$ until the solution turned clear. Upon turning clear, the temperature was reduced to $120^{\circ} \mathrm{C}$ and $100 \mathrm{mg}$ of Se powder was added via solid addition funnel and the solution was heated to $240{ }^{\circ} \mathrm{C}$, leading the color to evolve from clear to yellow to orange indicating the nucleation and growth of CdSe quantum dots. Once the quantum dots reached the appropriate size, heat was removed, and the reaction was quenched in a room temperature oil bath. The CdSe quantum dots were purified in a $\mathrm{N}_{2}$ filled glovebox. One crash-out using toluene as the solvent and $\mathrm{MeOH}$ as the antisolvent was performed and the resulting material was dissolved in toluene and cleaned once by gel permeation chromatography with Biobeads SX-1. ${ }^{3} \mathrm{H}$ NMR shows that there are no free ligands exchanging with the surface. The synthetic batch was portioned out and the toluene removed in vacuo. The CdSe QDs used for electrochemical measurements were first dissolved in $0.15 \mathrm{M}$ ${ }^{n} \mathrm{Bu}_{4} \mathrm{PF}_{6}$ THF and then, $0.15 \mathrm{M}^{\mathrm{n}} \mathrm{Bu}_{4} \mathrm{PF}_{6} \mathrm{CH}_{3} \mathrm{CN}$ was added slowly to the THF/CdSe QD solution in order to create the $90 / 10 \mathrm{CH}_{3} \mathrm{CN} / \mathrm{THF}$ electrolyte mixture. This CdSe QD solution, once made, was discarded after 1 day. Concentrations of CdSe QDs were calculated according to the solution's absorbance at $\lambda_{\max }{ }^{4}$

Electrochemical simulations were performed with DigiElch v.8. The initial voltammogram was modeled with the calculated diffusion coefficient of the associated ferrocene derivative. The standard heterogeneous rate constant, $\mathrm{k}_{\mathrm{s}}$, was fit for the first voltammogram and this value was used in the subsequent modelling with CdSe. Utilizing the above parameters, the voltammograms with CdSe were fit by floating the values of $\mathrm{K}_{1}, \mathrm{~K}_{2}, \mathrm{k}_{1}$ and $\mathrm{k}_{2}$. In order to create fidelity within the model, the same $K_{1}, K_{2}, k_{1}$ and $k_{2}$ values were used for the fitting of three concentrations of added $\mathrm{CdSe}$. The concentration of the ferrocene derivative after dilution with the CdSe stock solution was corrected within the simulation. 


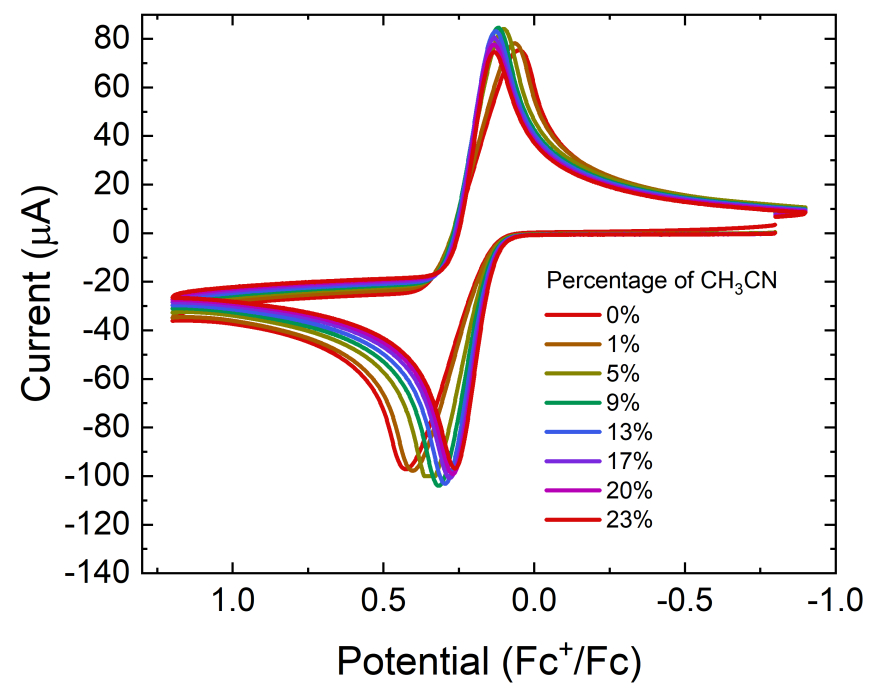

Figure S1. CVs of $5.0 \mathrm{mM}$ ferrocene upon addition of $\mathrm{CH}_{3} \mathrm{CN}$ to THF, Glassy carbon working electrode, $\mathrm{Pt}$ auxiliary electrode, Ag wire pseudo reference, $0.15 \mathrm{M}\left[{ }^{\left.\mathrm{n} B \mathrm{u}_{4} \mathrm{~N}\right]\left[\mathrm{PF}_{6}\right]} 100 \mathrm{mV} / \mathrm{s}\right.$.

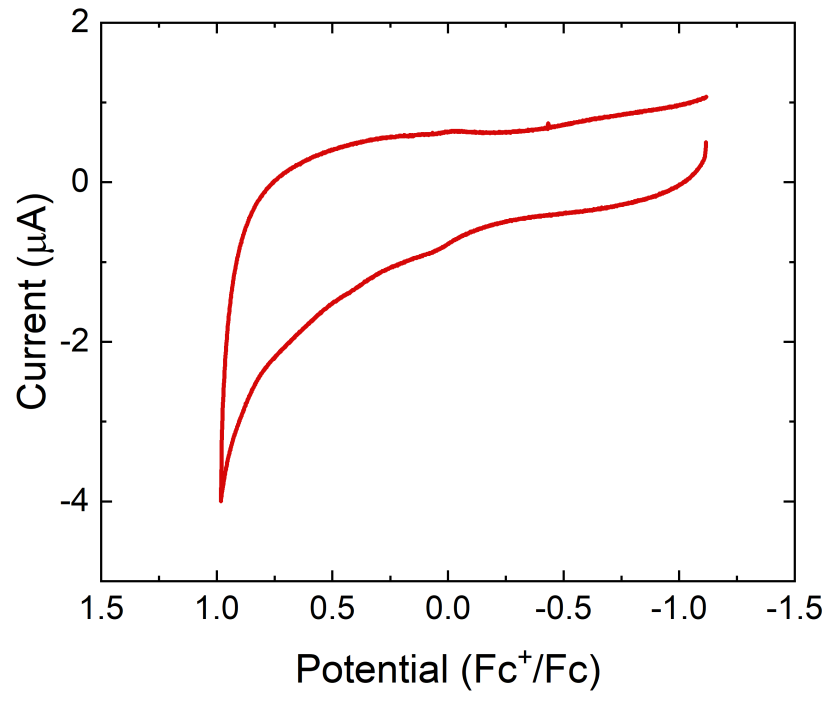

Figure S2. CV of $0.4 \mathrm{mM}$ CdSe QDs to demonstrate lack of electrochemical response from CdSe QDs in the region of 0.8 to $-0.1 \mathrm{~V}$ vs $\mathrm{Fc}^{+} / \mathrm{Fc}$. Glassy carbon working electrode, $\mathrm{Pt}$ auxiliary electrode, $\mathrm{Ag}$ wire

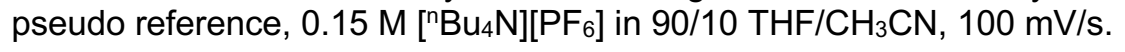




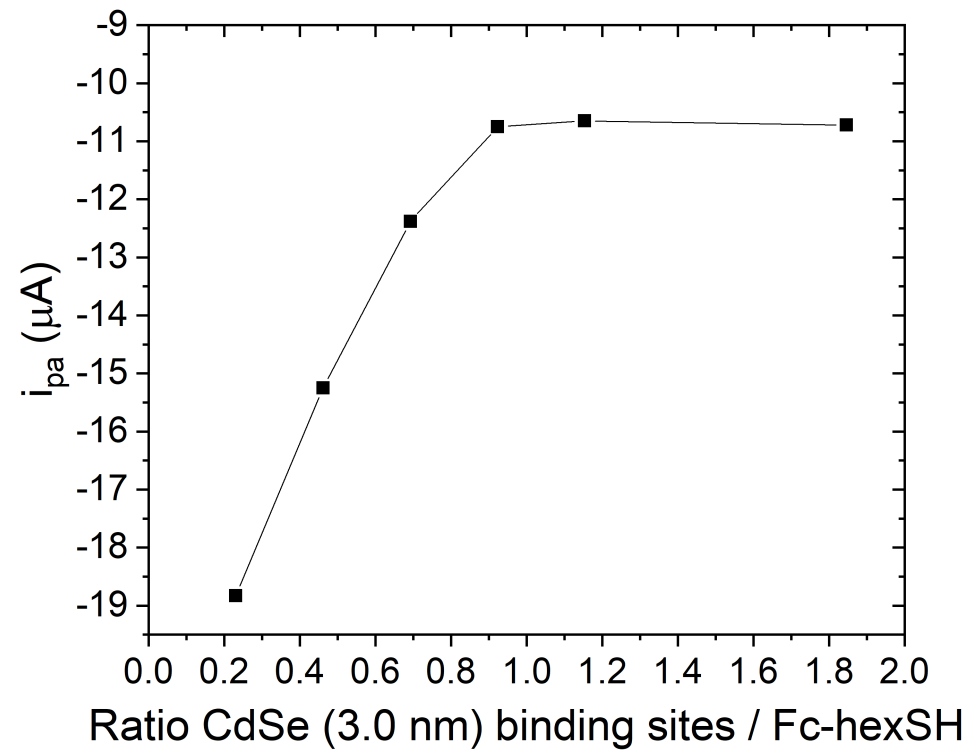

Figure S3. ipa $(\mu \mathrm{A})$ versus ratio of CdSe QD $(3.0 \mathrm{~nm})$ binding sites to [Fc-hexSH].

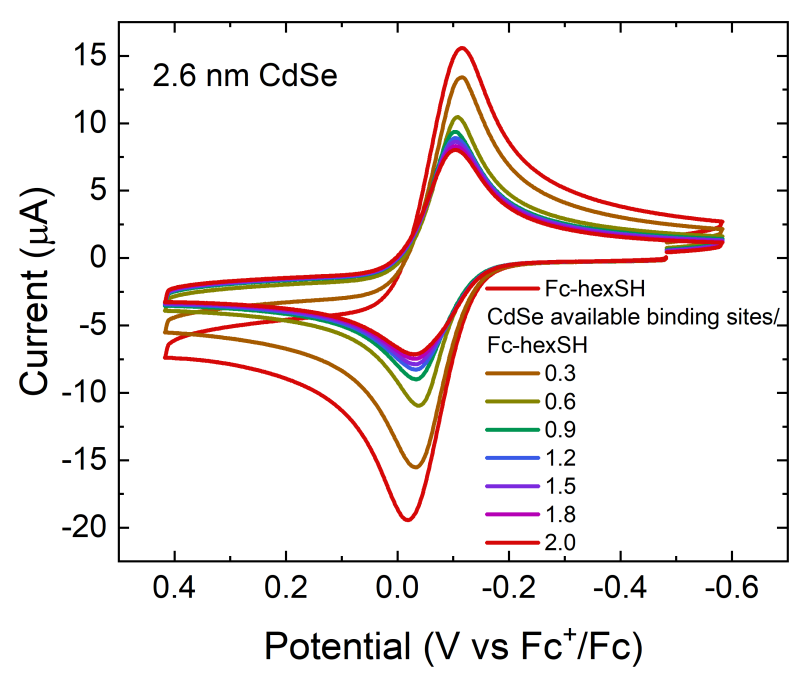

Figure S4. CVs of $1.1 \mathrm{mM} \mathrm{Fc-hexSH} \mathrm{(first} \mathrm{trace,} \mathrm{no} \mathrm{CdSe} \mathrm{QDs)} \mathrm{with} \mathrm{increasing} \mathrm{amounts} \mathrm{of} 0.3 \mathrm{mM}$ CdSe QD (2.6 nm diameter) solution aliquots. Legend shows the ratio of Fc-hexSH in terms of available binding sites calculated on the CdSe QDs. Glassy carbon working electrode, Pt auxiliary electrode, Ag wire pseudo reference, $0.15 \mathrm{M}\left[{ }^{\mathrm{n}} \mathrm{Bu}_{4} \mathrm{~N}\right]\left[\mathrm{PF}_{6}\right]$ in 90/10 $\mathrm{THF} / \mathrm{CH}_{3} \mathrm{CN}, 100 \mathrm{mV} / \mathrm{s}$. 


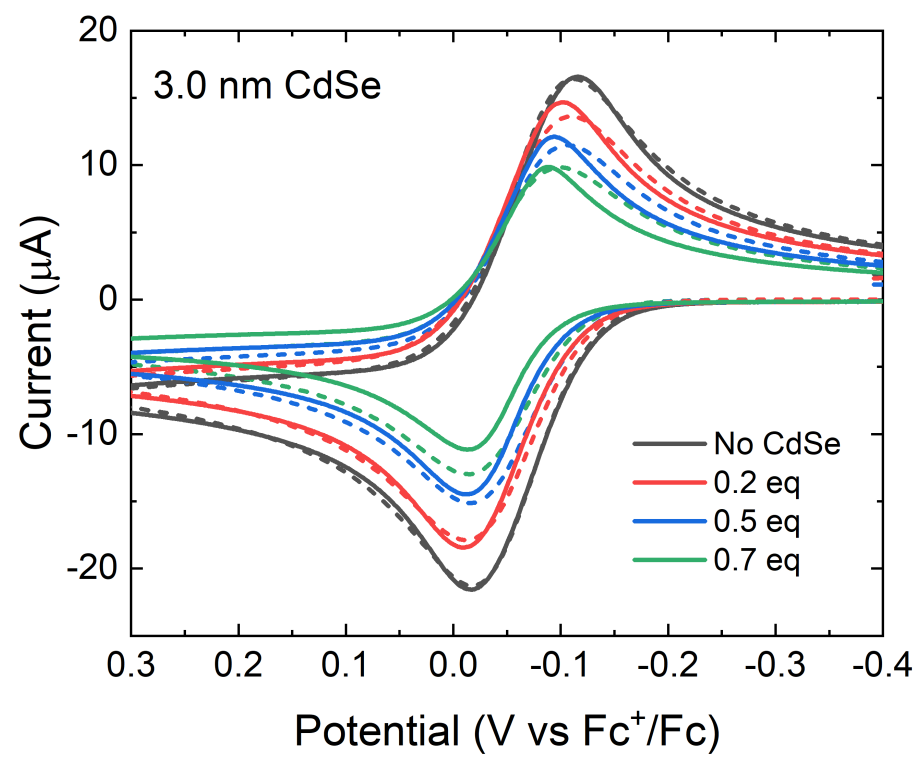

Figure S5. CVs of 1.3 mM Fc-hexSH with 5.9, 11.5 and 17.0 $\mu \mathrm{M} 3.0 \mathrm{~nm}$ CdSe QD, solid lines indicate data and dashed lines indicate simulation; $0.15 \mathrm{M}\left[\mathrm{nBu}_{4}\right]\left[\mathrm{PF}_{6}\right], 90 / 10 \mathrm{THF} / \mathrm{CH}_{3} \mathrm{CN}$, glassy carbon working, $\mathrm{Pt}$ aux and Ag wire ref, $100 \mathrm{mV} / \mathrm{s}$. Equivalents given include the number of calculated binding sites on the CdSe QDs.

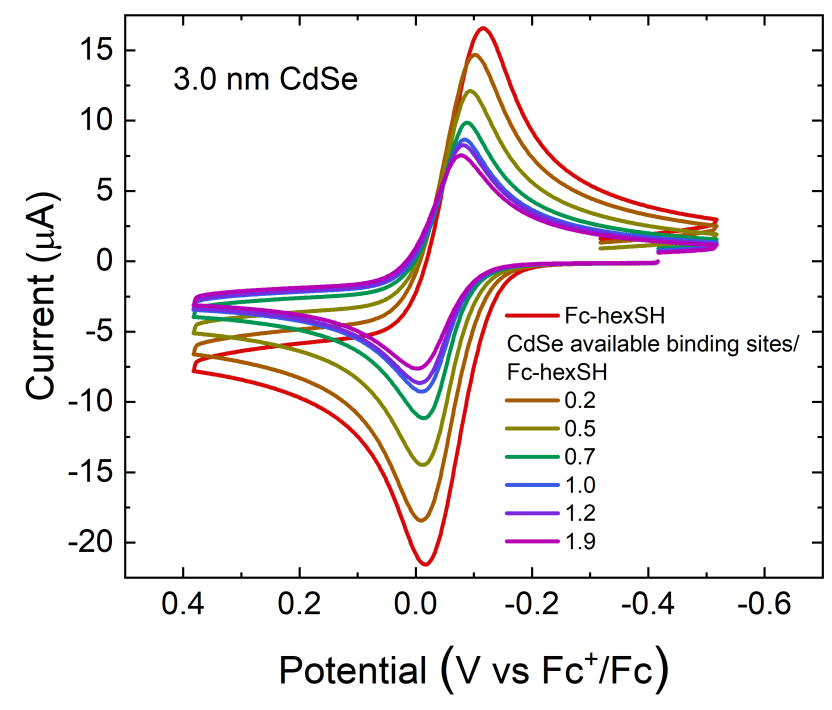

Figure S6. CVs of $1.3 \mathrm{mM}$ Fc-hexSH (first trace, no CdSe QDs) with increasing amounts of $0.3 \mathrm{mM}$ CdSe QD (3.0 nm diameter) solution aliquots. Legend shows Fc-hexSH/CdSe QD binding site ratio.Glassy

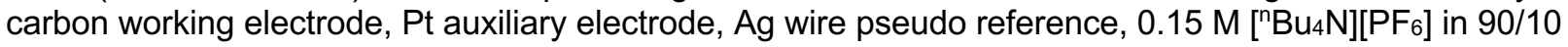
$\mathrm{THF} / \mathrm{CH}_{3} \mathrm{CN}, 100 \mathrm{mV} / \mathrm{s}$. 


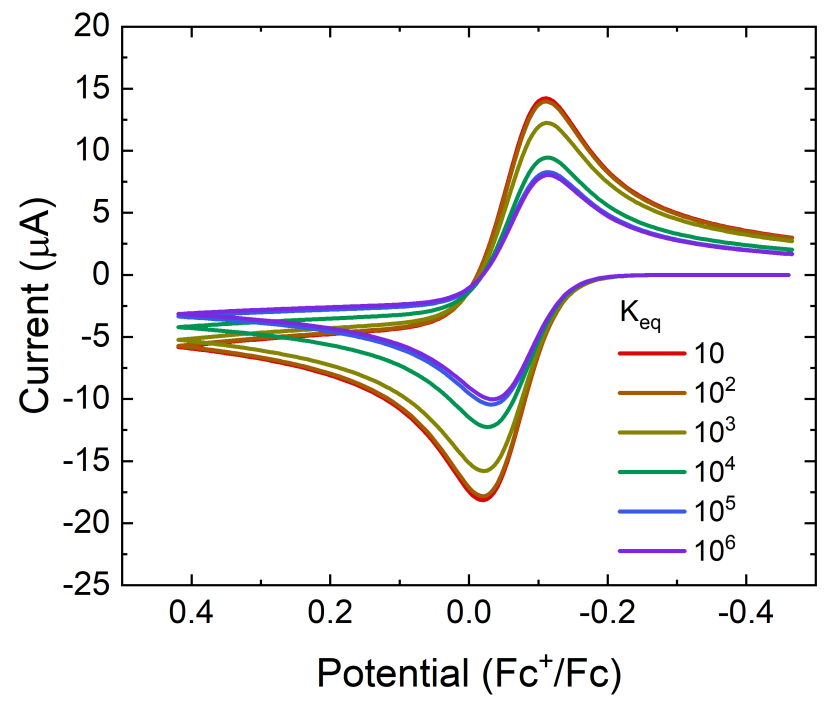

Figure S7. CV simulations performed with different magnitudes of Keq for Fc-hexSH with $17.0 \mu \mathrm{M}$ of 2.6 nm CdSe QDs.

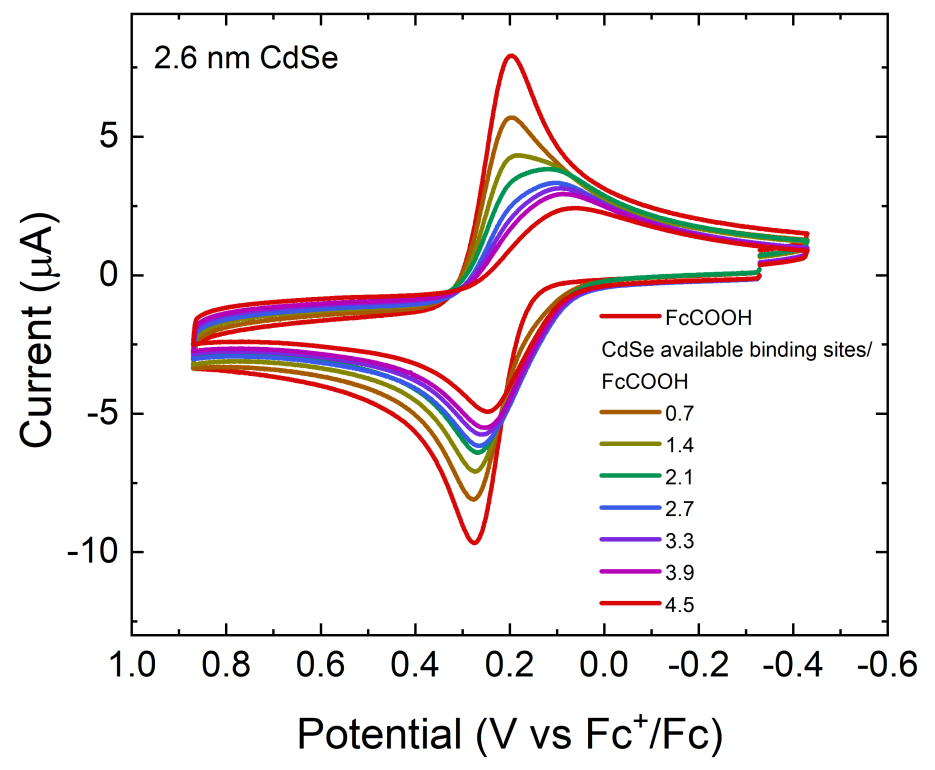

Figure S8. CVs of $0.4 \mathrm{mM} \mathrm{FcCOOH}$ (first trace, no CdSe QDs) with increasing amounts of $0.3 \mathrm{mM}$ CdSe QD $(2.6 \mathrm{~nm})$ solution aliquots. Legend shows FcCOOH/CdSe QD binding site ratio. Glassy carbon working electrode, $\mathrm{Pt}$ auxiliary electrode, Ag wire pseudo reference, $0.15 \mathrm{M}\left[{ }^{\mathrm{n}} \mathrm{Bu}_{4} \mathrm{~N}\right]\left[\mathrm{PF}_{6}\right]$ in 90/10 $\mathrm{THF} / \mathrm{CH}_{3} \mathrm{CN}, 100 \mathrm{mV} / \mathrm{s}$. 


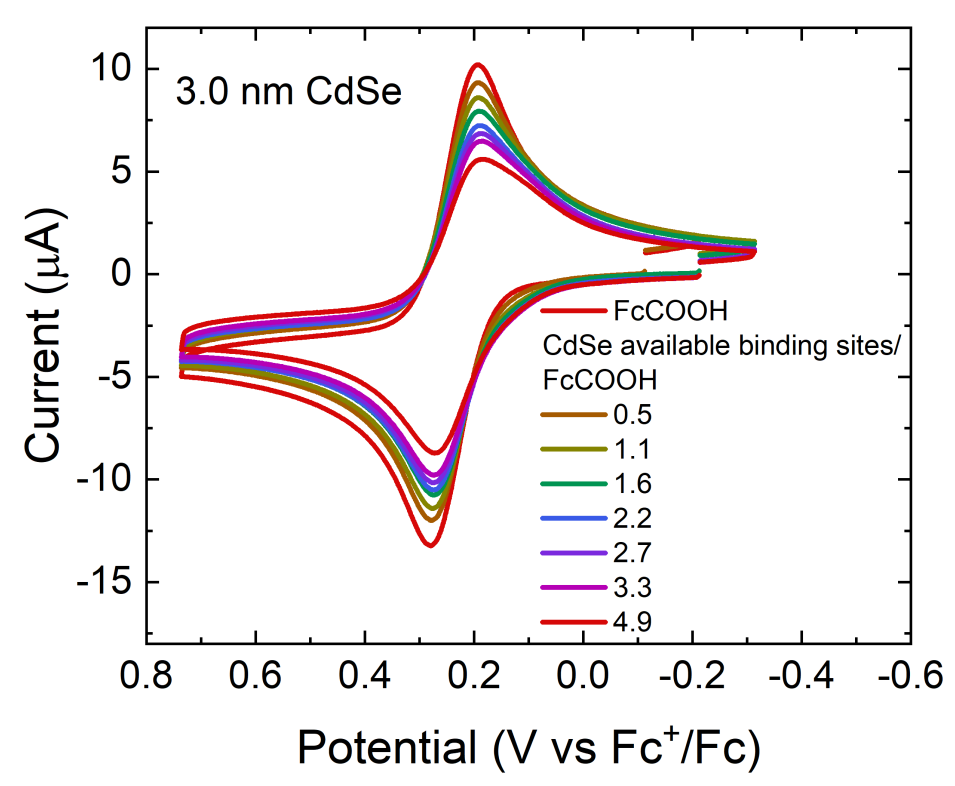

Figure S9. CVs of $0.6 \mathrm{mM} \mathrm{FcCOOH}$ (first trace, no CdSe QDs) with increasing amounts of $0.3 \mathrm{mM}$ CdSe $\mathrm{QD}(3.0 \mathrm{~nm})$ solution aliquots. Legend shows $\mathrm{FcCOOH} / \mathrm{CdSe} \mathrm{QD}$ binding site ratio.Glassy carbon working electrode, $\mathrm{Pt}$ auxiliary electrode, Ag wire pseudo reference, $0.15 \mathrm{M}\left[{ }^{\mathrm{n}} \mathrm{Bu}_{4} \mathrm{~N}\right][\mathrm{PF} 6]$ in 90/10 $\mathrm{THF} / \mathrm{CH}_{3} \mathrm{CN}, 100 \mathrm{mV} / \mathrm{s}$.

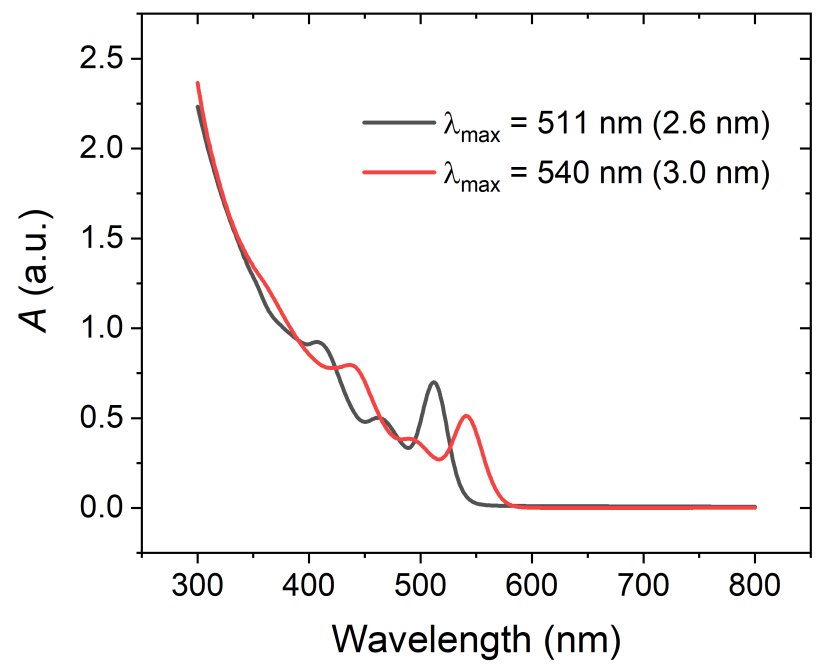

Figure S10. UV-vis absorption spectra of CdSe QD samples used in this study. 


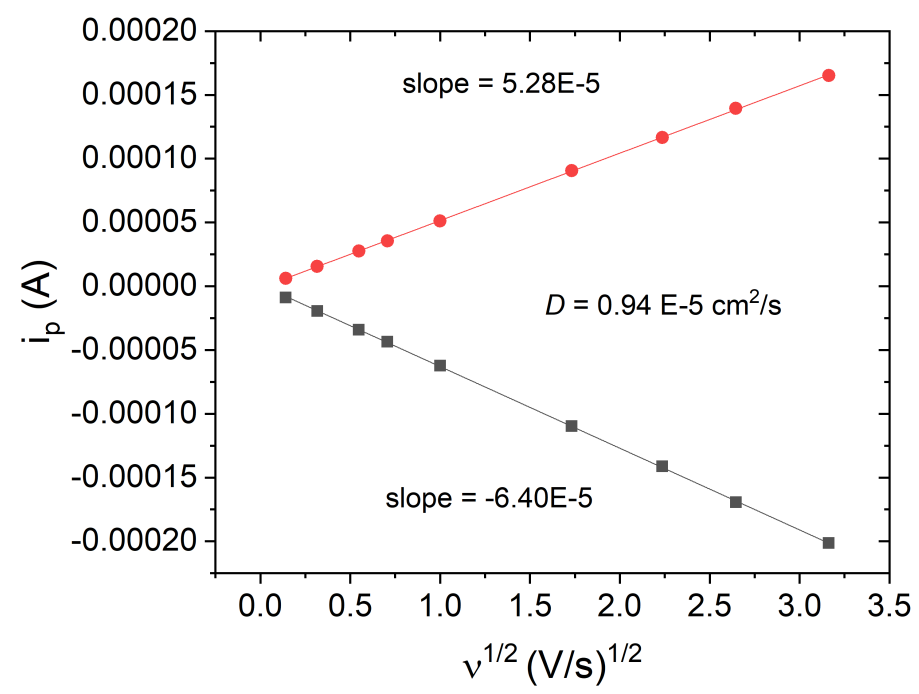

Figure S11. Peak current (ip) versus square root of scan rate $\left((\mathrm{V} / \mathrm{s})^{1 / 2}\right)$ of $1 \mathrm{mM} \mathrm{Fc-hexSH}$ in $0.15 \mathrm{M}$ $\left[{ }^{\mathrm{n}} \mathrm{Bu}_{4} \mathrm{~N}\right]\left[\mathrm{PF}_{6}\right]$ in $90 / 10 \mathrm{THF} / \mathrm{CH}_{3} \mathrm{CN}$ for the calculation of the $\mathrm{Fc}-$ hexSH diffusion coefficient.

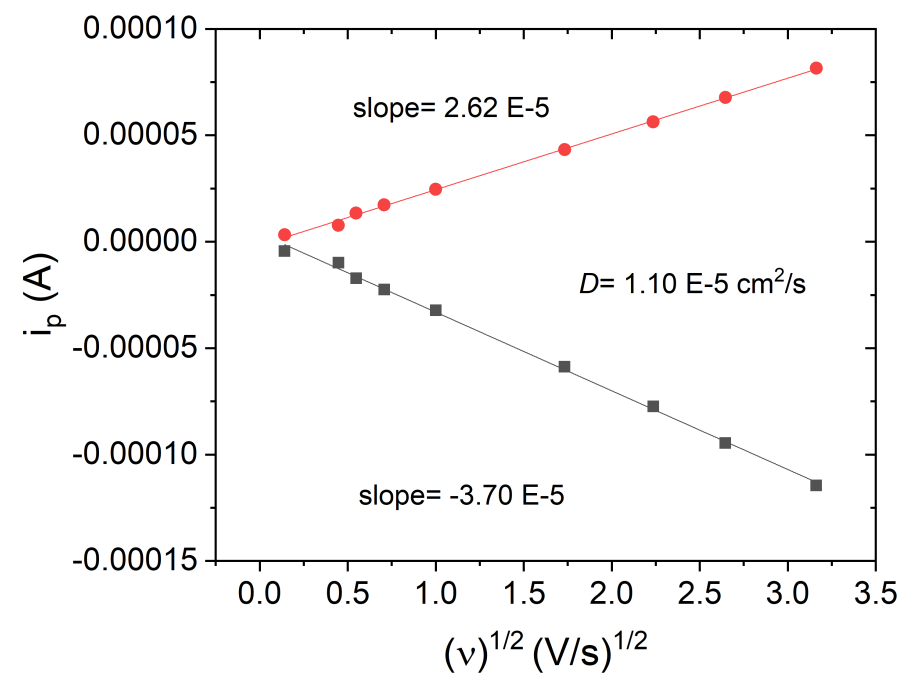

Figure S12. Peak current $\left(\mathrm{i}_{\mathrm{p}}\right)$ versus square root of scan rate $\left((\mathrm{V} / \mathrm{s})^{1 / 2}\right)$ of $1 \mathrm{mM} \mathrm{FcCOOH}$ in $0.15 \mathrm{M}$

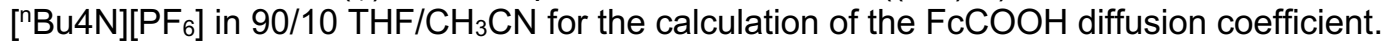


Table S1. Fitting parameters used for electrochemical simulations

\begin{tabular}{|c|c|c|c|c|}
\hline & $\begin{array}{l}\text { Fc-hexSH/ } 3.0 \mathrm{~nm} \\
\text { CdSe QDs }\end{array}$ & $\begin{array}{c}\text { Fc-hexSH/2.6 nm } \\
\text { CdSe QDs }\end{array}$ & $\begin{array}{l}\text { FcCOOH/3.0 nm } \\
\text { CdSe QDs }\end{array}$ & $\begin{array}{l}\mathrm{FcCOOH} / 2.6 \mathrm{~nm} \\
\mathrm{CdSe} \text { QDs }\end{array}$ \\
\hline $\mathrm{K}_{1}\left(\mathrm{Fc}^{+}-\mathrm{CdSe}\right)$ & $1 \mathrm{E} 6$ & $1 \mathrm{E} 6$ & 12,283 & 36,848 \\
\hline $\mathrm{K}_{2}(\mathrm{Fc}-\mathrm{CdSe})$ & $1.863 \mathrm{E} 6$ & $6.000 \mathrm{E} 5$ & 400 & 1,200 \\
\hline $\mathrm{kf}\left(\mathrm{Fc}^{+}-\mathrm{CdSe}\right)$ & 1000 & 1000 & 10 & 100 \\
\hline kf(Fc-CdSe) & 1000 & 1000 & 10 & 100 \\
\hline 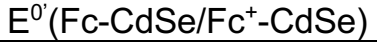 & -0.02 & -0.08 & 0.15 & 0.15 \\
\hline $\mathrm{E}^{0^{\prime}}\left(\mathrm{Fc} / \mathrm{Fc}^{+}\right)$ & -0.066 & -0.066 & 0.238 & 0.238 \\
\hline $\mathbf{\alpha}_{\left(\mathrm{FC}-/ \mathrm{FC}^{+}-\right)}$ & 0.5 & 0.5 & 0.5 & 0.5 \\
\hline $\mathbf{\alpha}_{(\mathrm{Fc}-\mathrm{CdSe} / \mathrm{FC}+-\mathrm{CdSe})}$ & 0.5 & 0.5 & 0.5 & 0.5 \\
\hline $\mathrm{k}_{\mathrm{s}}(\mathrm{cm} / \mathrm{s})\left(\mathrm{Fc} / \mathrm{Fc}^{+}\right)$ & 0.007 & 0.008 & 0.015 & 0.03 \\
\hline $\begin{array}{c}\mathrm{ks}_{\mathrm{s}}(\mathrm{cm} / \mathrm{s})\left(\mathrm{Fc}-\mathrm{CdSe} / \mathrm{Fc}^{+}-\right. \\
\mathrm{CdSe})\end{array}$ & 0.007 & 0.008 & 0.015 & 0.03 \\
\hline
\end{tabular}

\section{References}

(1) Jasieniak, J.; Bullen, C.; van Embden, J.; Mulvaney, P. Phosphine-Free Synthesis of CdSe Nanocrystals. J. Phys. Chem. B 2005, 109 (44), 20665-20668. https://doi.org/10.1021/jp054289o.

(2) Chambrier, I.; Banerjee, C.; Remiro-Buenamañana, S.; Chao, Y.; Cammidge, A. N.; Bochmann, M. Synthesis of Porphyrin-CdSe Quantum Dot Assemblies: Controlling Ligand Binding by Substituent Effects. Inorg. Chem. 2015, 54 (15), 7368-7380. https://doi.org/10.1021/acs.inorgchem.5b00892.

(3) Shen, Y.; Gee, M. Y.; Tan, R.; Pellechia, P. J.; Greytak, A. B. Purification of Quantum Dots by Gel Permeation Chromatography and the Effect of Excess Ligands on Shell Growth and Ligand Exchange. Chem. Mater. 2013, 25 (14), 2838-2848. https://doi.org/10.1021/cm4012734.

(4) Jasieniak, J.; Smith, L.; van Embden, J.; Mulvaney, P.; Califano, M. Re-Examination of the SizeDependent Absorption Properties of CdSe Quantum Dots. J. Phys. Chem. C 2009, 113 (45), 19468-19474. https://doi.org/10.1021/jp906827m. 